\title{
A GAMIFICAÇÃO APLICADA EM AMBIENTES DE APRENDIZAGEM
}

\author{
Marcelo Luis Fardo - Programa de Pós-Graduação em Educação - Universidade de \\ Caxias do Sul. Contato: marcelofardo@yahoo.com.br
}

Resumo: Este artigo tem a finalidade de oferecer um conceito para o fenômeno da gamificação, que vem ganhando visibilidade por sua capacidade de criar experiências significativas quando aplicada em contextos da vida cotidiana. Recentemente, a sua aplicação vem sendo observada na educação, o que justifica a sua pesquisa aprofundada, a fim de descobrir os melhores caminhos para a sua utilização. Após a conceituação, segue uma breve descrição de um relato sobre a utilização da gamificação em um ambiente de aprendizagem e, por fim, algumas linhas gerais para a sua aplicação.

Palavras-chave: games, gamificação, aprendizagem, ambiente de aprendizagem, método de ensino.

\section{GAMIFICATION APPLIED TO LEARNING ENVIRONMENTS}

Abstract: This article aims to provide a concept for the gamification phenomenon, which is gaining visibility because of its ability to create meaningful experiences when applied in contexts of everyday life. Recently, its application has been observed in education, which justifies more deep research in order to find the best ways to make good uses of it. After this conceptualization, a brief description of a report about the use of gamification in a learning environment follows and, in the end, some guidelines for its application.

Keywords: games, gamification, learning, learning environment, teaching methods.

\section{INTRODUÇÃO}

Os games (jogos digitais) são uma forma de entretenimento bastante popular entre públicos de todas as idades. Nos EUA, quase todas as residências possuem pelo menos um dispositivo com capacidade para rodar games comerciais (computador, console, smartphone), quase metade das residências possui um console de videogame e a idade média do jogador é de trinta anos (ESA, 2012). No Brasil, o impacto dessa indústria não é tão grande, mas mesmo assim é bastante significativo: cerca de $23 \%$ dos brasileiros são jogadores assíduos ou casuais, o que corresponde a cerca de 45 milhões de jogadores (ORRICO, 2012). Sabemos também que os games são poderosas ferramentas para potencializar aprendizagens em diversas áreas do conhecimento (AZEVEDO e BOMFOCO, 2012, PESCADOR, 2010) e que existe uma área dedicada à aplicação de games na aprendizagem, chamada de Digital Game-Based Learning (DGBL) (VAN ECK, 2006) que, entre os seus focos de aplicação, está a utilização de games comercias para a aprendizagem de determinados conteúdos escolares (AZEVEDO, 2012).

Dentro desse contexto vemos surgir um novo fenômeno, chamado de gamificação (WERBACH e HUNTER, 2012), que consiste na utilização de elementos dos games (mecânicas, estratégias, pensamentos) fora do contexto dos games, com a finalidade de motivar os indivíduos à ação, auxiliar na solução de problemas e promover aprendizagens (KAPP, 2012). Esse fenômeno vem se espalhando pela educação, aplicado como estratégia de ensino e aprendizagem, dirigida a um público-alvo inserido 
na chamada geração gamer, e existem resultados positivos sendo obtidos através dessas experiências (SHELDON, 2012).

Assim, este texto se propõe a conceituar a gamificação e descrever algumas linhas gerais de sua aplicação, com a finalidade de promover a discussão e aprofundamento sobre esse fenômeno emergente, cujo horizonte de adoção na educação em nosso país encontra-se em um futuro muito próximo (JOHNSON et al., 2012).

\section{GAMIFICAÇÃO}

Conforme mencionado, a gamificação é um fenômeno emergente, que deriva diretamente da popularização e popularidade dos games, e de suas capacidades intrínsecas de motivar a ação, resolver problemas e potencializar aprendizagens nas mais diversas áreas do conhecimento e da vida dos indivíduos. Esse potencial que os games apresentam já havia sido percebido há mais de três décadas (PAPERT, 2008). Porém, naquele tempo, a indústria dos games ainda estava se consolidando. Atualmente, podemos dizer que influência dessa forma de entretenimento é global e atinge praticamente todas as camadas da população.

Originada como método aplicado em programas de marketing e aplicações para web, com a finalidade de motivar, engajar e fidelizar clientes e usuários (ZICHERMANN e CUNNINGHAM, 2012), a gamificação pressupõe a utilização de elementos tradicionalmente encontrados nos games, como narrativa, sistema de feedback, sistema de recompensas, conflito, cooperação, competição, objetivos e regras claras, níveis, tentativa e erro, diversão, interação, interatividade, entre outros, em outras atividades que não são diretamente associadas aos games, com a finalidade de tentar obter o mesmo grau de envolvimento e motivação que normalmente encontramos nos jogadores quando em interação com bons games.

O objetivo é conseguir visualizar um determinado problema ou contexto e pensar soluções a partir do ponto de vista de um game designer (profissional responsável pela criação de jogos eletrônicos), já que esse profissional geralmente possui uma capacidade ímpar em produzir experiências que concentram a energia e o foco de muitos indivíduos para resolver problemas em mundos virtuais (MCGONIGAL, 2011). Porém, a gamificação não implica em criar um game que aborde o problema, recriando a situação dentro de um mundo virtual, mas sim em usar as mesmas estratégias, métodos e pensamentos utilizados para resolver aqueles problemas nos mundos virtuais em situações do mundo real.

Para situá-la e diferenciá-la de outros contextos semelhantes, a imagem abaixo (Figura 1) posiciona a gamificação entre dois eixos. O horizontal traz a ideia de um jogo (no caso, game) completo até as suas partes (elementos) e o vertical vai da brincadeira (livre e descontraída) para o jogo (mais formal). Sendo assim, a gamificação pressupõe o uso de elementos dos games, sem que o resultado final seja um game completo, e também se diferencia do design lúdico na medida em que este pressupõe apenas um aspecto de maior liberdade, de forma lúdica, quanto ao contexto em que está inserido. Em outras palavras, nessa concepção, abordar um problema de forma lúdica não implica em contemplar objetivos e seguir uma metodologia mais precisa, que é o que a gamificação propõe. 


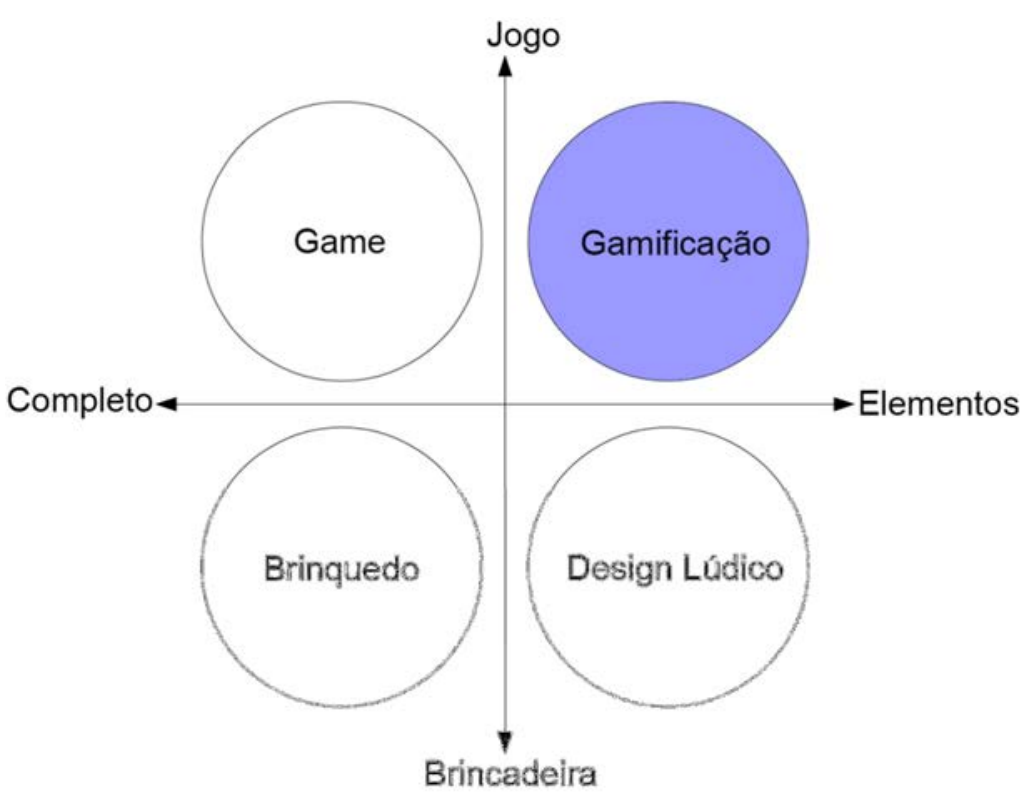

Figura 1 - Contextualização da gamificação (DETERDING et al., 2011).

Essa concepção de game, da qual a gamificação deriva, implica em concebê-lo como um sistema, composto por elementos interconectados que, ao agregarem-se em um todo, resulta em um fenômeno que é maior do que a soma de suas partes. Dessa forma, podemos utilizar desde um número reduzido de elementos, até uma quantia maior, fazendo com que o produto final possa produzir uma experiência próxima a de um game completo.

Quanto à escolha dos elementos, e de como aplicá-los em um contexto específico, isso depende da finalidade do projeto em questão. Podemos construir sistemas gamificados baseados apenas em pontos, medalhas e tabelas de líderes (PBL Points, Badges and Leaderboards), que são apenas as mecânicas mais básicas de um game, com a finalidade única de promover mudanças no comportamento dos indivíduos através de recompensas extrínsecas, semelhantes às ideias da economia comportamental (LADLEY, 2011), ou podemos construir uma experiência significativa que vá muito além do que as mecânicas básicas dos games oferecem e motivar intrinsecamente os indivíduos a desempenharem os seus papéis da melhor forma possível dentro do contexto em que se encontram (WERBACH e HUNTER, 2012).

Assim, a gamificação se apresenta como um fenômeno emergente com muitas potencialidades de aplicação em diversos campos da atividade humana, pois a linguagem e metodologia dos games são bastante populares, eficazes na resolução de problemas (pelo menos nos mundos virtuais) e aceitas naturalmente pelas atuais gerações que cresceram interagindo com esse tipo de entretenimento. Ou seja, a gamificação se justifica a partir de uma perspectiva sociocultural.

Atualmente, a gamificação encontra na educação formal uma área bastante fértil para a sua aplicação, pois lá ela encontra os indivíduos que carregam consigo muitas aprendizagens advindas das interações com os games. Encontra também uma área que necessita de novas estratégias para dar conta de indivíduos que cada vez estão mais inseridos no contexto das mídias e das tecnologias digitais e se mostram desinteressados pelos métodos passivos de ensino e aprendizagem utilizados na maioria das escolas. 


\section{MULTIPLAYER CLASSROOM: UMA EXPERIÊNCIA DE UTILIZAÇÃO DA GAMIFICAÇÃO EM UM AMBIENTE DE APRENDIZAGEM}

Conforme o que foi exposto, a gamificação é um fenômeno emergente e, por isso, existem poucos relatos de experiências empíricas em processos educacionais, devido ao fato de que os educadores precisam dominar bem essa linguagem antes de serem capazes de utilizá-la em seus projetos, o que normalmente ainda não ocorre em nossa realidade. Sem um conhecimento aprofundado sobre a gamificação, aplicá-la na educação pode impactar de forma não esperada os processos de ensino e aprendizagem. Pode ainda ser empregada de forma incorreta ou equivocada, reforçando mais ainda alguns problemas presentes no sistema de ensino atual como, por exemplo, o fato de ocorrer uma valorização maior das notas obtidas do que da aprendizagem em si (LEE e HAMMER, 2011). Isso pode acontecer se, ao aplicarmos a gamificação, utilizarmos apenas as mecânicas mais básicas dos games e com isso construirmos somente um sistema mais complexo de pontuação, por exemplo.

Um relato bastante completo sobre uma experiência bem sucedida de aplicação da gamificação está contido no livro Multiplayer Classroom: Designing Coursework as a Game, do professor norte-americano Lee Sheldon (2012). Nele, esse professor, que saiu da indústria de games para ensinar game design (disciplina que estuda a criação de jogos eletrônicos) em uma Instituição de Ensino Superior, resolveu utilizar os seus conhecimentos sobre games (pensamentos, estratégias, mecânicas) para projetar e conduzir suas aulas sobre game design. Ou seja, o professor Sheldon gamificou as suas disciplinas.

Através da potencialização do aspecto interacionista dos games, o professor promoveu algumas mudanças no projeto e na condução de suas disciplinas. Resumidamente, vamos elencar algumas das mudanças que este método desencadeou e que são relatadas nessa obra:

- O feedback, na forma de notas, sofreu dois processos de mudança para se assemelhar ao que ocorre nos games. Primeiro, a nota passou a ser incremental, ou seja, o professor fazia questão de enfatizar, no início do semestre que os alunos, naquele momento, possuíam nota zero e que a partir daí iriam construí-la através das atividades propostas. A segunda é que, assim como nos games, várias tarefas pontuadas precisaram ser pensadas, em detrimento do que geralmente ocorre, onde apenas duas ou três avaliações são disponibilizadas. Isso proporcionou um maior número de oportunidades de sucesso para os estudantes, através de um contato maior com os conhecimentos a serem construídos;

- A linguagem utilizada foi transformada para corresponder àquela dos jogos RPGs online. Assim, os alunos formavam agrupamentos, chamados de guildas, criavam personagens para interagir nas atividades, as tarefas eram consideradas como missões, fazer exercícios virou derrotar inimigos, entre outras mudanças executadas para criar para os estudantes, através da utilização da narrativa, uma experiência parecida com a de estarem interagindo com um game e imersos em um mundo virtual;

- As notas finais eram resultado da quantidade de pontos obtidos pelos personagens criados pelos alunos/jogadores. Assim, o foco não ficava restrito na nota final, mas incorporava também a evolução dos personagens, através do acúmulo desses pontos, o que era conseguido através do cumprimento das missões propostas (atividades de aula, tarefas, trabalhos, apresentações, pesquisas, entre outros); 
- O espaço físico da sala de aula foi modificado para acomodar as guildas (grupos de alunos) e esses espaços possuíam uma denominação advinda de algum elemento dos games, o que determinava o tipo de atividade que seria executada naquele espaço. Durante o semestre, as guildas iam revezando esses espaços, o que fazia com que todos interagissem com as propostas neles desenvolvidas. Por exemplo, um desses espaços era denominado de Zona da Imersão e a guilda que estivesse ocupando esse espaço deveria executar tarefas sobre o conceito de imersão relacionado aos games;

- O erro recebeu um tratamento diferente. Nos games, sempre há uma nova chance de obter sucesso, sempre existe uma nova tentativa para abordar o problema de uma forma diferente a fim de obter sucesso. Assim, o professor precisava pensar e avaliar um número maior de atividades e desempenhos dos alunos, o que contribuía também para tirar as notas finais do foco da aprendizagem.

Com essas e outras mudanças, o professor introduziu a linguagem dos games para promover a aprendizagem sobre desenvolvimento de games. O método de ensino era o próprio objetivo da aprendizagem. Entretanto, para não restringir a aplicação da gamificação em um curso voltado apenas para a área de game design, vários artigos foram inseridos no decorrer do livro, com o relato de experiências de professores ao redor do mundo que utilizaram esses métodos em outras áreas do conhecimento, da educação infantil ao ensino superior, com resultados positivos.

Segundo as descrições deste professor, essa experiência aumentou os níveis de interesse, participação e motivação dos seus estudantes e promoveu uma maior interação entre eles, o que contribuiu para que o conhecimento fosse construído de uma forma diferente do que observamos tradicionalmente, através de aulas expositivas, em que o professor apenas fala e propõe atividades enquanto os alunos escutam e executam ordens.

O autor também atenta para a gamificação, dizendo que teve essa inspiração advinda dos games algum tempo antes desse termo ganhar terreno, tanto na academia como na indústria, e observa que, na verdade, não interessa se a gamificação é um fenômeno passageiro ou se veio pra ficar. O que importa é que os resultados que ele obteve com seus alunos foram positivos (e isso refletiu também na opinião dos próprios alunos sobre este processo, na medida em que a maioria deles avaliou a experiência como positiva) e, enquanto assim for, essa estratégia continuará sendo utilizada por ele.

\section{LINHAS GERAIS PARA UTILIZAÇÃO DA GAMIFICAÇÃO}

Conforme o que foi dito, para aplicar a gamificação como método a fim de transformar processos de ensino e aprendizagem através da utilização de estratégias e pensamentos dos games, com a intenção de aproximar esses processos dos indivíduos da geração gamer, algumas linhas gerais podem ser tomadas como ponto de partida. Para isso, tomamos como base a proposta de criação de uma plataforma gamificada online de aprendizagem para escolas em Portugal (SIMÕES et al., 2012) e algumas indicações para aplicação da gamificação em negócios, organizações e instituições (WERBACH e HUNTER, 2012). Essa proposta de Portugal considera um ambiente virtual online de aprendizagem (apesar de potencializar a gamificação através dos seus recursos, as tecnologias digitais não são um requisito para a sua aplicação). Assim, os seguintes apontamentos são considerados: 
- Disponibilizar diferentes experimentações: assim como em grande parte dos games, muitas vezes não há um único caminho que conduz ao sucesso. Propiciar diferentes caminhos para alcançar a solução de um problema incorpora diferentes características pessoais de aprendizagem no processo educativo, o que contribui para a experiência educativa de cada um;

- Incluir ciclos rápidos de feedback: nos games os jogadores são sempre capazes de visualizar o efeito de suas ações em tempo real. Nas escolas normalmente acontece o inverso e os alunos só conseguem visualizar seus resultados depois de certo tempo, muito maior do que aquele que estão acostumados nos games. Acelerar esse processo de feedback estimula a procura por novos caminhos para atingir os objetivos, bem como o redirecionamento de uma estratégia, caso ela não esteja apresentando os resultados esperados;

- Aumentar a dificuldade das tarefas conforme a habilidade dos alunos: nos bons games os jogadores sempre encontram desafios no limite de suas habilidades. Proporcionar diferentes níveis de dificuldade para os desafios propostos pode auxiliar na construção um senso de crescimento e avanço pessoal nos estudantes, e também faz com que cada um siga o seu próprio ritmo de aprendizagem;

- Dividir tarefas complexas em outras menores: nos games, os objetivos maiores normalmente são divididos em uma série de outros menores e mais fáceis de serem superados. Dessa forma, o estudante vai construindo seu conhecimento de forma gradual, observando as partes do problema e de que modo elas se relacionam com o todo, proporcionando maior motivação e preparo para superar o desafio maior inicial;

- Incluir o erro como parte do processo de aprendizagem: o erro faz parte dos games de forma natural. Nenhum jogador espera interagir com um game sem se deparar com a falha várias vezes. Na aprendizagem sistematizada, o erro normalmente não é bem tolerado. Incluir e aceitar o erro como parte do processo de aprendizagem e estimular a reflexão dos motivos desses erros faz parte de um processo semelhante ao que ocorre nos games;

- Incorporar a narrativa como contexto dos objetivos: nos games normalmente temos um motivo para as ações dos personagens, uma história que justifica o porquê de estarem fazendo aquilo. Muitas aprendizagens ocorrem fora de contexto e os estudantes têm dificuldade em entender os motivos de estarem se dedicando a aquilo, de relacionar a parte com o todo. Construir um contexto para a aprendizagem pode fornecer um bom motivo para os estudantes empenharem suas energias em aprender;

- Promover a competição e a colaboração nos projetos: dois aspectos fundamentais dos games são a competição e a colaboração, e eles não precisam ser mutuamente exclusivos. Esses elementos podem ocorrer juntos com a narrativa e pode haver competição entre grupos, o que potencializa a interação e pode fornecer mais um contexto para os objetivos;

- Levar em conta a diversão: a aprendizagem pode (e nossa opinião é que deve) ser prazerosa. Nas séries inicias existe um consenso que aprender pode ser divertido. Após isso, a seriedade deve imperar. Os bons games são divertidos por uma série de motivos não abordados aqui e, conforme as evidências das pesquisas apontadas indicam, são também boas ferramentas para a aprendizagem. Pensar esse aspecto na educação pode melhorar a 
experiência que os indivíduos têm dentro dos ambientes de aprendizagem, o que acaba por potencializar a aprendizagem como um todo;

Essas são algumas das orientações para um método que se proponha a buscar uma aproximação com o que ocorre nos games e com o modo como os indivíduos inseridos nessa cultura estão mais acostumados a interagir com os problemas e com suas aprendizagens. Vale lembrar que não existe um único caminho para aplicar a gamificação, tanto por este ser um fenômeno emergente quanto pelo fato de que os games possuem vários elementos e, sendo assim, várias são as possibilidades de aplicação. Consequentemente, vários podem ser os resultados finais obtidos.

\section{CONSIDERAÇÕES FINAIS}

Se a gamificação é apenas uma onda com os dias contados ou é um fenômeno que vai impactar sobre boa parte dos serviços e produtos que usamos, e inclusive na educação, isso somente o tempo poderá responder. O que faz deste um fenômeno que merece atenção é a sua atual situação emergente, que parece ainda estar em ritmo de subida, o que se verifica pelas crescentes utilizações e consequentes pesquisas e estudos sendo publicados. A popularidade dos games só aumentou até hoje, o que justifica o fato de que a incorporação da gamificação nesses serviços e produtos não pareça forçada, mas sim natural.

Longe de ser pensada como o remédio para todos os males da educação, a gamificação precisa, antes de tudo, ser compreendida como um todo para, aí sim, analisarmos a sua aplicação nos contextos educacionais, identificando se ela realmente potencializa a aprendizagem e a participação dos indivíduos ou se seus métodos e resultados não conseguem atender as expectativas criadas em torno desse fenômeno. Entendemos que a sua utilização nesse contexto requer uma boa dose de compreensão por parte dos professores, e que esse é particularmente um dos grandes desafios em nossa realidade. Porém, a ideia é que a gamificação possa ser vista como mais um caminho em busca das soluções que a educação no século XXI demanda.

Talvez uma de suas grandes vantagens seja a de proporcionar um sistema em que os estudantes consigam visualizar o efeito de suas ações e aprendizagens, na medida em que fica mais fácil compreender a relação das partes com o todo, como acontece nos games. Da mesma forma, um dos objetivos principais de introduzirmos uma experiência assim é para que os indivíduos sintam que seus objetivos contribuem para algo maior e mais importante, que suas ações fazem sentido dentro de uma causa maior, que é o que os elementos dos games podem proporcionar se utilizados de forma cuidadosa, da mesma forma que conseguem dentro dos mundos virtuais.

O entendimento também se faz necessário para não tomar a gamificação como um simples método de estímulo à mudança de comportamento através da introdução de um sistema de feedback mais eficiente, por exemplo. Com os elementos dos games, dispomos de ferramentas valiosas para criar experiências significativas, que podem impactar de forma positiva a experiência educacional dos indivíduos, pois ela pode fornecer um contexto para a construção de um sentido mais amplo para a interação, tanto nas escolas como em outros ambientes de aprendizagem, potencializando a participação e a motivação dos indivíduos inseridos nesses ambientes. 


\section{REFERÊNCIAS}

AZEVEDO, Victor de Abreu. Jogos eletrônicos e educação: construindo um roteiro para a sua análise pedagógica. Renote - Novas Tecnologias na Educação - UFRGS, Porto Alegre. V. 10 n $^{\circ}$ 3, 2012.

BOMFOCO, Marco Antônio; AZEVEDO, Victor de Abreu. Os jogos eletrônicos e suas contribuições para a aprendizagem na visão de J. P. Gee. Renote - Novas Tecnologias na Educação - UFRGS, Porto Alegre. V. 10 nº 3, 2012.

DETERDING, S.; DIXON, D.; KHALED, R.; NACKE, L. From Game Design Elements to Gamefulness: Defining “Gamification”. In: Proceedings of the 15th International Academic MindTrek Conference: Envisioning Future Media Environments (MindTrek '11). ACM, Nova Iorque, EUA. Disponível em: $<$ http://85.214.46.140/niklas/bach/MindTrek_Gamification_PrinterReady_110806_SDE _accepted_LEN_changes_1.pdf>. Acesso em: 15 abr 2013.

ESA. Entertainment Software Association: 2012 Essential Facts About the Computer and Video Game Industry. EUA, 2012. Disponível em <http://www.theesa.com/facts/pdfs/ESA_EF_2012.pdf>. Acesso em 29 abr. 2013.

JOHNSON, L.; ADAMS BECKER, S.; CUMMINS, M.; ESTRADA, V.; MEIRA, A. Perspectivas tecnológicas para o ensino fundamental e Médio Brasileiro de 2012 a 2017: Uma análise regional por NMC Horizon Project . Austin, Texas: The New Media Consortium, Estados Unidos, 2012. Disponível em: <http://zerohora.clicrbs.com.br/pdf/14441735.pdf>. Acesso em: 07 mar. 2013.

LADLEY, Paul. Gamification, Education and Behavioural Economics. Games-ED Innovation in Learning, 2011.

LEE, Joey J.; HAMMER, Jessica. Gamification in Education: What, How, Why Bother? Academic Exchange Quarterly. 2011. Disponível em $<$ http://www.gamifyingeducation.org/files/Lee-Hammer-AEQ-2011.pdf>. Acesso em: 05 mai. 2013.

KAPP, Karl. The Gamification of Learning and Instruction: Game-based Methods and Strategies for Training and Education. Pfeiffer, 2012.

MCGONIGAL, Jane. Reality Is Broken: Why Games Make Us Better and How They Can Change The World. Nova Iorque: The Penguin Press, 2011.

ORRICO, Alexandre. Mercado brasileiro de games já o quarto maior do mundo e deve continuar a crescer. O Estado de São Paulo, São Paulo. 08 out. 2012. Disponível em: <http://www1.folha.uol.com.br/tec/1165034-mercado-brasileiro-de-games-ja-e-oquarto-maior-do-mundo-e-deve-continuar-a-crescer.shtml>. Acesso em: 01 mai. 2013.

PAPERT, Seymour. A Máquina das Crianças: Repensando a Escola na Era da Informática. Trad. Sandra Costa. Porto Alegre: Artmed, 2008. 
PESCADOR, Cristina M. Ações de Aprendizagem Empregadas pelo Nativo Digital para Interagir em Redes Hipermidiáticas tendo o Inglês como Língua Franca. Dissertação (Mestrado) - Universidade de Caxias do Sul, Programa de Pós-Graduação em Educação, 2010.

SHELDON, Lee. The Multiplayer Classroom: Designing Coursework as a Game. Boston, MA: Cengage Learning, 2012.

SIMÕES, J.; REDONDO, R. D.; VILAS, A. F. A social gamification framework for a K-6 learning platform. Computers in Human Behavior, 2012. Disponível em: <http://dx.doi.org/10.1016/j.chb.2012.06.007>. Acesso em: 15 mar. 2013.

VAN ECK, Richard. Digital game based learning: It's not just the digital native who are restless. Educause Review, vol. 41, pg. 16-30, 2006. Disponível em:

<http://net.educause.edu/ir/library/pdf/ERM0620.pdf>. Acesso em: 05 mar. 2013.

WERBACH, Kevin; HUNTER, Dan. For The Win: How Game Thinking Can Revolutionize Your Business. Filadélfia, Pensilvânia: Wharton Digital Press, 2012.

ZICHERMANN, Gabe; CUNNINGHAM, Christopher. Gamification by Design. Implementing Game Mechanics in Web and Mobile Apps. Canada: O’Reilly Media, 2011. 